\title{
Post-traumatic stress disorder in the critically ill patients
}

\section{Roop Kishen}

It is well known that exposure to severe psychological stress, such as major disasters, earthquakes, war and other major life-threatening events, causes psychological and mental problems in the victims of such events; one such psychological problem being post-traumatic stress disorder (PTSD). Critical illness, by its very nature, is a life-threatening event; and as intensive care medicine has progressed, survival of some of the sickest patients seen in clinical practice has become a reality. Treatment of critically ill in the intensive care unit (ICU) involves medication (sedatives, analgesics), operations and other painful procedures. Survivors of critical illness face a prolonged period of recovery due to physical weakness, malnutrition, breathlessness, loss of muscle mass and cognitive dysfunction. There may also be a recall of unpleasant events and experiences, e.g., events associated with mechanical ventilation. Withdrawal from sedatives and analgesics, as well as depression caused by slow and prolonged physical recovery, adds to the problems of these patients. It is not surprising that critical illness should cause psychological disorders in surviving patients.

PTSD is a psychological condition that is triggered by experiencing or witnessing of life-threatening events, these events being extreme in nature,,$^{[1]}$ not necessarily outside the normal range of human experience but such as to arouse intense fear, helplessness or horror (DSMIV-TR $p$ 463). ${ }^{[2]}$ PTSD is characterized by various symptoms such as flashbacks (repeated reliving the

\section{From:}

Intensive Care Unit, Hope Hospital, Stott Lane, Salford, Manchester, M6 8HD, UK

Correspondence:

Intensive Care Unit, Hope Hospital, Stott Lane, Salford, Manchester, M6 8HD, UK. E-mail: roop.kishen@manchester.ac.uk events in intrusive memories) and nightmares (reexperiencing the event); both these re-experiences occur against a background of numbness or emotional blunting. Increased arousal (increased vigilance, an enhanced startle reaction, inability to sleep) and avoidance (of the situations that remind one of the traumatic events) are also common symptoms of this disorder. ${ }^{[2]}$ Anxiety and depression with suicidal ideas often accompany PTSD. It may also be complicated by excessive alcohol or drug use. Generally, all individuals involved in extreme events will experience some emotional symptoms, and these will be related to the stressor event; this is common behavior. Some individuals have symptoms lasting for a few weeks (but less than a month), and these may be regarded as 'normal' grief reaction, e.g., grief from sudden bereavement. These symptoms are self limiting and are referred to as acute stress disorder. Acute PTSD is diagnosed when the symptoms have lasted for 1-3 months as against chronic PTSD, where symptoms have lasted for more than 3 months. The importance of this distinction lies in the fact that active treatment in acute PTSD may reduce the high risk of developing chronic PTSD $\left[{ }^{[1]}\right.$ PTDS is generally not present if symptoms have occurred more than 6 months after experiencing the traumatic event. Although level of exposure to traumatic stressor is directly related to the psychological impact, other factors contribute to development of PTSD. Thus history of previous mental disorders, previous trauma, child abuse, as well as socioeconomic and demographic factors and ethnicity, appear to be risk factors for vulnerability to PTSD. ${ }^{[3]}$

It is estimated that about $8 \%$ of population in the United States will experience PTSD at some point in their lives, with women (10.4) twice as likely as men (5\%). ${ }^{[4]}$ In the 
United Kingdom, about $1 \%$ of general population suffer from PTSD. ${ }^{[5]}$ Women seem to be at higher risk than their male counterparts; however, the mechanisms of this gender difference are not clear. ${ }^{[6]}$ Of the number of people who experience a traumatic event, only a subset will ultimately develop PTSD. Individual differences are important, and neither trauma exposure nor a strong family history of the disorder is sufficient to cause PTSD; and it is thought that in adults, the presence of, and interplay among, the three factors, viz., traumatic event, recovery environment and genetics, is responsible for vulnerability to PTSD. ${ }^{[7]}$

PTSD is known to occur after events such as wars, especially in war veterans, where it as been extensively studied. ${ }^{[8]}$ Anxiety and depression are also well known to be associated with chronic illnesses like cardiovascular disease. However, association of PTSD with survivors of critical illness is a relatively new field of medicine. One of the earliest studies in this regard was that of Schelling and colleagues. ${ }^{[9]}$ In their study of survivors after acute respiratory distress syndrome ( $n=87 ; 80$ completed questionnaires), these authors found that although most survivors reported a high level of perceived health-related quality of life, $27.5 \%$ scored above threshold value on the post-traumatic stress syndrome 10-Question inventory, which is highly predictive of PTSD. They also found worse short form 36 mental health domain scores and increased incidence of PTSD in those patients who recalled more than one distressing symptoms than those who recalled one or no symptoms. In a long-term followup of these survivors (median 8 years, range 3-13), it was observed that presence of PTSD symptoms at hospital discharge is associated with persistent PTSD. ${ }^{[10]}$ No baseline variable predicted the risk of development of PTSD; however, the length of ICU stay was 2.5 times longer in those who later developed PTSD. ${ }^{[10]}$

There have been various attempts to define predictors of PTSD. Brain imaging studies have shown that brain areas sensitive to stress, such as hippocampus, may well be involved in development of PTSD. In the first study of its kind, $8 \%$ decrease in magnetic resonance imaging based right hippocampal volume was found in patients with post-war PTSD. ${ }^{[11]}$ Chronic PTSD patients have also been shown to have lowered plasma ${ }^{[12]}$ or urinary ${ }^{[13]}$ cortisol levels and higher noradrenergic activity. ${ }^{[14]}$ Road traffic accident victims with low plasma cortisol levels immediately after accident ${ }^{[15]}$ or low urinary cortisol excretion for the first $15 \mathrm{~h}$ after the accident ${ }^{[16]}$ are at higher risk of developing the disorder. Evidence to the contrary exists as well; thus increased levels of urinary cortisol were found in women ${ }^{[17]}$ with PTSD and in men with recent-onset PTSD. ${ }^{[18]}$ These discrepancies may be due to the fact that PTSD patients represent a very heterogeneous population and it may thus be difficult to determine whether these neuroendocrine changes are responsible for development of PTSD or secondary effects of the disorder. ICU patients often receive exogenously administered stress hormones such as epinephrine, norepinephrine and steroids. Evidence is accumulating that these stress hormones may cause consolidation of emotional memory, ${ }^{[19]}$ and this may theoretically increase incidence of PTSD because of the direct relationship between PTSD and number of events recalled. Studies in this regard have shown that whereas administration of exogenous epinephrine and hydrocortisone appears to enhance consolidation of memory for adverse experiences in ICU, they seem to be protective with regard to development of PTSD. ${ }^{[20]}$ Although steroid treatment does not reduce the number or categories of traumatic recall, it produces a significant reduction in PTSD symptoms. ${ }^{[21]}$ This protective effect of steroids can possibly be explained by steroid-related impairment in traumatic memory retrieval as well as possible extinction of traumatic memories. ${ }^{[21]}$

In contrast to findings of Shelling et al., ${ }^{[9]}$ a study by Jones et al. ${ }^{[22]}$ has shown that the content of recalled ICU memories was more important than the number of those memories in development of PTSD. They showed that delusional memories (such as hallucinations, nightmares, etc.) cause more and persistent emotional distress than the factual, albeit unpleasant, memories (such as pain, anxiety, etc.). Thus, whereas Shelling et al. ${ }^{[9]}$ suggest that total amnesia of ICU experience as achieved by sedatives is helpful in preventing PTSD from developing, Jones et al. ${ }^{[22]}$ argue that complete amnesia is difficult to achieve and that delirious memories (possibly promoted by sedatives) cause more psychological problems. Sedation has also been shown to promote depressive symptoms; in a study of patients with acute lung injury, development of depressive and PTSD symptoms was directly related to the number of days on sedation. ${ }^{[23]}$ In this regard, Kress et al.. ${ }^{[24]}$ have shown that daily interruption of sedation in ventilated ICU 
patients reduces the incidence of PTSD, lending support to the findings by Jones et al. ${ }^{[22]}$

PTSD is a chronic disabling disease, causing untold misery in the sufferers. Unfortunately, often depression, alcohol and drug abuse, anxiety disorders and suicidal behavior complicate the disorder and the lives of the patients. Various strategies to treat and prevent the disorder have been suggested. Treatment of PTSD is a specialized field, and detailed discussion is outside the scope of this paper. Single- and multiple-session psychotherapy, self-help rehabilitation manual and followup help by regular telephone contact, pharmacotherapy with antidepressants have all been advocated. Serotonin reuptake inhibitors have been shown to be particularly useful, probably because of their effect on hippocampal volume. ${ }^{[25]}$ Guidelines for detailed treatment of PTSD are described elsewhere. ${ }^{[26]}$

Important questions still need to be asked: Why is only a subset of population at risk of developing PTSD? What are the preventive strategies in the critically ill? Are the medications unique to ICU care (sedatives, analgesics, catecholamines, etc.) in anyway responsible for development of this disorder, and if yes, is there any way we can modify use of these drugs so that our patients are less at risk of developing PTSD? How do we educate patients, relatives and colleagues to work together in preventing PTSD and helping the survivors with this disorder? With time and further research, we hope to have answers to many of these questions. However, at present, routine use of corticosteroids in preventing PTSD cannot be recommended without further research.

\section{References}

1. The expert consensus guideline series. Treatment of Posttraumatic Stress Disorder. The Expert Consensus Panels for PTSD. J Clin Psychiatry 1999;60:3-76.

2. DSM - IV-TR diagnostic Criteria for acute stress disorder and post-traumatic stress disorder. American Psychiatric Association: 2000.

3. Yehuda R, editor. Risk factors of post-traumatic stress disorder. American Psychiatric Press Inc: Washington, DC; 1999.

4. What is PTSD? National Centre for PTSD. United States department of veterans affairs. http:/www.ncptsd.va.gov/topcis/ gen_info_ptsd.html (access checked 24th September 2006).

5. Jones C, Griffiths RD. Physical and psychological recovery. In:
Intensive care aftercare. Griffiths RD, Jones C, editors. Butterworth-Heinemann: Edinburgh; 2002. p. 51-65.

6. Holbrook TL, Hoyt DB, Stein MB, Sieber WJ. Gender differences in long-term post-traumatic stress disorder outcomes after trauma:Women are at higher risk of adverse outcomes than man. J Trauma 2002;53:882-8.

7. Ballenger JC, Davidson JR, Lecrubier Y, Nutt DJ, Marshall RD, Nemeroff $C B$, et al. Consensus statement update on posttraumatic stress disorder from the International Consensus Group on depression and anxiety. J Clin Psychiatry 2004;65: 55-62.

8. Pitman RK, Altman B, Macklin ML. Prevalence of post-traumatic stress disorder in wounded Vietnam veterans. Am J Psychiatry 1989;146:667-9.

9. Schelling G, Stoll C, Haller M, Briegel J, Manert W, Hummel T, et al. Health-related quality of life and post-traumatic stress disorder in survivors of the acute respiratory distress syndrome. Crit Care Med 1998;26:651-9.

10. Kapfhammer HP, Rothenhäusler HB, Krauseneck T, Stoll C, Schelling G. Post-traumatic stress disorder and health-related quality of life in long-term survivors of acute respiratory distress syndrome. Am J Psychiatry 2004;161:45-52.

11. Bremner JD, Randall P, Scott TM, Bronen RA, Seibyl JP, Southwick SM, et al. MRI-based measurement of hippocampal volume in patients with combat-related post-traumatic stress disorder. Am J Psychiatry 1995;152:973-81.

12. Yehuda R, Giller EL, Southwick SM, Lowy MT, Mason JW. Hypothalamic-pituitary-adrenal dysfunction in post-traumatic stress disorder. Biol Psychiatr 1991;30:1031-48.

13. Mason JW, Giller EL, Kosten TR, Ostroff RB, Podd L. Urinary free cortisol levels in post-traumatic stress disorder patients. $J$ Nerv Mental Dis 1986;174:145-9.

14. Mason JW, Giller EL, Kosten TR, Harkness L. Elevation of urinary norepinephrine/cortisol ratio in post-traumatic stress disorder. $J$ Nerv Ment Dis 1988;176:498-502.

15. McFarlane AC, Atchison M, Yahuda R. The acute stress response following motor vehicle accidents and its relation to PTSD. Ann N Y Acad Sci 1997;821:437-41.

16. Delahanty DI, Raimonde AJ, Spoonster E. Initial post-traumatic urinary cortisol levels predict subsequent PTSD symptoms in motor vehicle accident victims. Biol Psychiatr 2000;48:940-7.

17. Lemieux AM, Coe CL. Abuse-related post-traumatic stress disorder: Evidence for chronic neuroendocrine activation in women. Psychosom Med 1995;57:105-15.

18. Hawk LW, Dougall AL, Ursano RJ, Baum A. Urinary catecholamines and cortisol in recent onset post-traumatic stress disorder after motor vehicle accidents. Psychosomat Med 2000;62:423-34 
19. Buchanan TW, Lovello WR. Enhanced memory for emotional material following stress-level cortisol treatment in humans. Psychoneuroendocrinology 2001;26:307-17.

20. Schelling G. Effects of stress hormones on traumatic memory formation and the development of post-traumatic stress disorder in critically ill patients. Neurobiol Learn Mem 2002;78:596-609.

21. Shelling G, Roozendaal B, De Quervain DJ. Can post-traumatic stress disorder be prevented with glucocorticoids? Ann NY Acad Sci 2004;1032:158-66.

22. Jones C, Griffiths RD, Humphries G, Skirrow PM. Memory, delusions and the development of acute post-traumatic stress disorder-related symptoms after intensive care. Crit Care Med 2001;29:573-80.

23. Nelson BJ, Weinert CR, Bury CL, Marinelli WA, Gross CR. Intensive care drug use and subsequent quality of life in acute lung injury patients. Crit Care Med 2000;28:3626-30.
24. Kress JP, Gehlbach B, Lacy M, Pliskin N, Pohlman AS, Hall JB. The long-term psychological effects of daily sedative interruption on critically ill patients. Am J Respir Crit Care Med 2003;168:1457-61.

25. Bremner JD, Vermetten E. Neuroanatomical changes associated with pharmacotherapy in post-traumatic stress disorder. Ann N Y Acad Sci 2004;1032:154-7.

26. Practice guideline for the treatment of patients with acute stress disorder and post-traumatic stress disorder. American Psychiatry Association: 2004. http://www.psych.org/ psych_pract/treatg/pg/prac_guide.cfm (access checked $25^{\text {th }}$ September 2006).

Source of Support: Nil, Conflict of Interest: None declared. 